\title{
A inscrição subjetiva da Lei e o adolescente em medida socioeducativa
}

\section{Subjective application of the Law and adolescents in socio- educational measures}

\section{La inscripción subjetiva de la Ley y el adolescente en una medida socioeducativa}

\author{
Carolina Esmanhoto Bertol* \\ Universidade Federal de Santa Catarina - UFSC, Florianópolis, Santa Catarina, Brasil
}

\section{Mériti de Souza**}

Universidade Federal de Santa Catarina - UFSC, Florianópolis, Santa Catarina, Brasil

\begin{abstract}
RESUMO
Neste trabalho problematiza-se a inscrição subjetiva da Lei utilizando-se o recorte conceitual da Lei simbólica no plano psicanalítico, como aquela que insere o sujeito na cultura, e da lei no campo jurídico e social que regula as ações dos sujeitos que compartilham de uma mesma rede social. Recorre-se a referenciais psicanalíticos e psicossociais para analisar os sentidos dos atos infracionais cometidos por um adolescente que cumpre medida socioeducativa de internação no estado do Paraná, considerando-se sua relação com a Lei simbólica e com a lei jurídica. A partir da análise entendese que os atos infracionais não afirmam a falta de inscrição subjetiva da Lei, mas antes, representam a possibilidade do adolescente compartilhar dos ideais propostos pela lógica liberal capitalista. Ou seja, a lógica liberal capitalista produz demandas excludentes entre si: obedecer às leis jurídicas e alcançar os ideais de êxito financeiro e social. Assim, para alcançar os ideais sociais o adolescente pode transgredir a lei jurídica, porém, essa transgressão não diz respeito à falta de inscrição subjetiva da Lei simbólica.

Palavras-chave: leis, subjetividade, transgressão, psicanálise, medidas.
\end{abstract}

\begin{abstract}
The paper focuses on the law's subjective application by using a conceptual outline of the symbolic law in the psychoanalytic level as the one that places the subject in the culture, and law in legal and social fields that regulates individuals' actions who share the same social network. It refers to psychoanalytic and psychosocial frameworks to analyze senses of illegal acts committed by a teenager who complies with socio-educational measures in the State of Paraná, and considering his relationship with symbolic and legal laws. From the analysis performed, it is possible to understand that infractions do not claim a lack of subjective application of the law, but rather represents the possibility for adolescents to share the ideals proposed by the liberal capitalist logic. In other words, the liberal capitalist logic produces unique demands among themselves: comply with legal laws and achieve
\end{abstract}


ideals of social and financial success. Thus, to reach social ideals adolescents may violate the legal law; however, that infraction does not concern with the lack of subjective description of the symbolic Law.

Keywords: laws, subjectivity, infraction, psychoanalysis, measures.

\section{RESUMEN}

En este trabajo se problematiza la inscripción subjetiva de la ley utilizándose el recorte conceptual de la ley simbólica en el plano psicoanalítico, como aquella que inserta al sujeto en la cultura, y de la ley en el campo jurídico y social que regula las acciones de los sujetos que comparten la misma red social. Se recurre a referencias psicoanalíticos y psicosociales para analizar los sentidos de los actos de infracción cometidos por un adolescente que cumple una medida socioeducativa de internación en el Estado de Paraná, considerándose su relación con la ley simbólica y con la ley jurídica. A partir del análisis realizado se entiende que los actos de infracción no afirman la falta de inscripción subjetiva de la ley sino que representan la posibilidad de que el adolescente comparta los ideales propuestos por la lógica liberal capitalista. O sea, la lógica liberal capitalista produce demandas excluyentes entre sí: obedecer a las leyes jurídicas y alcanzar los ideales de éxito financiero y social. Así, para alcanzar los ideales sociales el adolescente puede transgredir la ley jurídica, sin embargo, esa transgresión no se refiere a la falta de inscripción subjetiva de la ley simbólica.

Palabras clave: leyes, subjetividad, transgresión, psicoanálisis, medidas.

\section{Introdução}

No Brasil, tem se discutido cada vez mais o envolvimento de adolescentes em atos infracionais. O número de jovens vítimas de violência também vem crescendo, pois segundo "O mapa da violência: os jovens do Brasil", em 2012 houve 149 mortes por 100 mil jovens, sendo que $71,1 \%$ das mortes ocorreram por causas externas, entre elas homicídios e acidentes de trânsito (Waiselfisz, 2014). Apesar desse cenário, os discursos midiáticos e projetos de lei no Congresso vêm apresentando o jovem como o principal causador da violência social, velando o fato de que esta mesma população é a que mais sofre com essa situação. Eles apresentam inúmeros motivos para explicar o envolvimento dos jovens com atos infracionais, entre eles, ressaltam a falta de uma punição mais dura, uma vez que os atos são julgados a partir do Estatuto da Criança e do Adolescente (ECA) e não pelo código penal (BRASIL, 1990). Já as políticas públicas muitas vezes trazem implícitas ideias que vinculam o cometimento do ato infracional a desestruturação familiar e sua incapacidade de oferecer limites e disciplina ao jovem, a vulnerabilidade do território ou ainda a uma característica da adolescência, fase na qual o jovem procura testar os limites, contrariar as regras, no intuito de fortalecer uma identidade (PARANÁ, 2006). 
Por um lado, o ato infracional é lido como determinado pela vulnerabilidade social produzida historicamente em muitos territórios periféricos. Por outro lado, as visões apresentadas individualizam o problema do ato infracional, reduzindo-o a uma ação deliberada na qual o que está em causa é uma identidade infratora de quem o comete e uma incapacidade da família de educar e dar contornos ao jovem. Há uma leitura de que a transgressão das leis expressa uma dificuldade de introjetar limites e de aceitar as restrições pulsionais operadas por figuras de autoridade, as quais seriam efeitos diretos de uma dificuldade de inscrição subjetiva da Lei.

A perspectiva que pretendemos para este trabalho é problematizar os sentidos atribuídos aos atos infracionais cometidos por adolescentes aos quais se destinam as medidas socioeducativas. Compreendendo a constituição subjetiva a partir da inscrição da Lei, tal como apresentada pela psicanálise e articulada às experiências do sujeito com a lei no campo jurídico e social. Entendemos que a subjetividade tem sua constituição embasada tanto por aspectos coletivos quanto singulares, ou seja, é uma produção do sujeito associada a uma configuração coletiva sócio-histórica. Na visão freudiana as operações identificatórias constituintes da subjetividade já apontam para esta impossibilidade de separação do que pertence ao plano social e do que pertence ao plano individual. Assim, entendemos que os atos infracionais cometidos por adolescentes envolvem uma configuração subjetiva singular articulada ao coletivo de discursos e práticas sociais.

A associação entre a introjeção da Lei, a introjeção da autoridade e a articulação com a figura paterna é central na psicanálise, principalmente Freud (1973b) ressalta que é da identificação com o pai, resultante do complexo de Édipo, que surge a instância do supereu. Este é responsável por regular as ações do eu e por imposições severas - no sentido de inflexibilidade nas ordens a serem cumpridas - quando o mesmo não se apresenta de acordo com um ideal também advindo desse processo de identificação. Para Freud (1973b), o ideal de eu é uma articulação das heranças arcaicas do sujeito, da articulação de suas exigências pulsionais e seu desejo, com as formações culturais. É, pois, a articulação entre as tendências pulsionais e a rede simbólica e social (Freud, 1973a e 1973b). Tanto a identificação quanto a introjeção da Lei simbólica decorreriam da ameaça de castração que teria o pai como operador, sendo então o agente que puniria através da castração o desejo incestuoso da criança voltado à mãe.

Nesse sentido, está presente na própria psicanálise a ideia de que nos tornamos moralmente responsáveis por medo da punição e do castigo. Essa ideia não deixa de estar presente em Freud (1973b) quando afirma que o supereu se instaura em função do medo da castração pela autoridade paterna. Porém, o próprio Freud e 
posteriormente Lacan, ressaltam que o temor da castração não equivale ao medo do castigo, e que a ideia de que alguém foi punido através da castração, já é ela mesma uma construção imaginária para lidar com a mesma (Lacan, 1999; Freud, 2012). Além disso, ainda que na descrição de Freud sobre o supereu, a ideia de castigo esteja presente, se efetivando através de uma perda, esta ocorre em função de uma troca que a criança faz, na qual ela aceita perder algo para ganhar algo em troca (Pellegrino, 1987a). Assim, a operação da castração e da inscrição da Lei tem como consequência uma restrição nas satisfações do sujeito, mas, ao mesmo tempo, abre a possibilidade de outras formas de satisfação e escolha objetal a partir de sua inserção na rede social.

Nesse sentido, Pellegrino (1987b) demonstra como esta Lei internalizada no Édipo não tem a função de destruir o desejo, pelo contrário, tem a função de organizá-lo para preservar a vida. A Lei é produto de Eros, das pulsões de ligação, e possibilita ao sujeito orientar-se em relação ao seu desejo, o que só é possível na articulação deste com a rede social. Portanto, a Lei internalizada com o Édipo não se reduz a lei jurídica e formal, por estar articulada a processos e desejos inconscientes. Embora diferentes, elas estão vinculadas, pois a interdição ao incesto se sustenta e se organiza a partir das interdições e prescrições culturais. Para pertencer a uma comunidade o sujeito necessita se submeter às leis compartilhadas por ela e que regem as relações entre ele e o outro. Portanto, tanto o pacto edípico como o pacto social se sustentam a partir de trocas. No primeiro o sujeito aceita a interdição do incesto em troca de inserir-se na cultura e encontrar outras formas de satisfação. No segundo o sujeito participa da sociedade, contribui para a sua manutenção e desenvolvimento, submete-se às suas leis em troca de garantias de bem-estar, reconhecimento, segurança física e emocional.

Retomamos então as ideias de Pellegrino (1987a) que aponta para a importância de analisar o pacto social em articulação ao pacto edípico, já que a sociedade brasileira apresenta o contrato social organizado pela lei da cidadania, da igualdade, da justiça para todos, porém, no cotidiano oferece tratamento desigual e não cumpre suas próprias leis contratuais. Segundo o autor, para a criança aceitar a Lei da interdição cultural ela tem que fazer uma renúncia que pode acontecer mais facilmente se suas vivências foram de respeito e de amor. Isso acontece porque a Lei conforme presente no desejo é uma Lei erotizada que interdita uma escolha e abre outras escolhas além da entrada da criança na sociedade. No decorrer da vida da criança o pacto edípico sexual se vincula com o pacto social a partir de caminhos que levam tanto o primeiro a ancorar o segundo quanto levam o segundo a confirmar ou infirmar o primeiro.

Por um lado, a inscrição psíquica da Lei regula as relações objetais do sujeito e, por outro lado, as leis jurídicas são produzidas para regular 
as relações entre os membros de uma sociedade e suas ações. Ao sujeito que não reprime seus interesses e impulsos em prol da comunidade, é destinada uma punição, que serve tanto para modificar suas intenções e fazer com que volte a reprimir seus impulsos, quanto de exemplo para que outros continuem valorizando a comunidade (Freud, 1973d; Freire Costa, 2003). O Direito aparece aí como um dispositivo que regula a troca necessária entre o sujeito e o outro, processo no qual ele aceita perder por um lado para ganhar por outro, estabelecendo-se um contrato, pelo menos no plano ideal.

Para Bobbio (1997), a formação de um Estado jurídico consolida a passagem de um estado natural, onde existiam vários Direitos que eram sustentados pela força de cada um, para um estado onde os bens e as forças são atribuídos a um soberano comum, fonte do Direito e que se manifesta por meio da lei. $O$ autor descreve a lei como uma norma que é geral, independente do indivíduo sobre o qual ela recai, aplicando-se a partir do princípio de igualdade, não sendo aceitas, portanto, particularidades. Ela é imposta pelo poder dominante, que estabelece normas e critérios que permitam às pessoas entenderem aquilo que é permitido ou não dentro da sociedade. As leis permitem àqueles que convivem em um grupo social julgarem as suas ações e as ações das pessoas com as quais convivem.

Buscando apontar algumas respostas a esta questão vale ressaltarmos que embora a aplicação da lei fundamente-se no princípio da igualdade, Freud (1973d) já apontava a dificuldade do exercício prático desse princípio. Isso porque a comunidade apresenta relações de poder desiguais, e as leis são instituídas para e por aqueles que exercem um domínio dentro dela. Quando nos aproximamos da realidade brasileira, verificamos que a legislação não é aplicada tal como se encontra no discurso formal, e que os operadores do direito aplicam a lei de acordo com a posição que o sujeito ocupa dentro da rede social, a qual varia em função de marcadores sociais de raça, gênero, classe social e etnia, fazendo com que aqueles que se aproximam aos ideais do homem branco e orientado pelos princípios burgueses tenham seus direitos assegurados pelos representantes da lei e tendo também seu direito de liberdade e de defesa assegurados quando praticam transgressões. Aqueles que se distanciam desse ideal têm seus direitos desrespeitados e são severamente punidos por suas ações, tornando-se responsáveis pelo "mal" que perturba a ordem social. Com objetivo de trabalhar a história e a cultura brasileiras nas suas relações com a constituição subjetiva da lei, Pellegrino (1987a) analisa o contrato social no Brasil em relação à Lei simbólica. Para o autor, é importante analisar o pacto social e o pacto edípico, já que a sociedade brasileira apresenta o contrato social organizado pela lei da cidadania, da igualdade, da justiça para todos, porém, no cotidiano 
oferece tratamento desigual e não cumpre suas próprias leis contratuais. $\mathrm{O}$ autor afirma que nas sociedades capitalistas, o pacto social é quebrado de forma constante, e situações como desemprego, injustiça, desrespeito, levam as pessoas a vivenciarem experiências de humilhação e sofrimento. Assim, alguns atos infracionais podem revelar a não inscrição da Lei simbólica por parte de quem os comete, porém outros atos infracionais podem revelar situações nas quais o contrato social é quebrado e as pessoas podem transgredir a lei como resposta a essa quebra contratual.

No texto em que analisa as relações, contribuições e principalmente os limites entre a psicanálise e a criminologia, Lacan (1998) aponta que a nenhum método será possível de objetivar o crime, pois ele carrega sempre uma relação de dependência com as leis sociais, com aquilo que a sociedade institui como norma. Aponta que a Lei se relaciona dialeticamente ao crime, pois ao mesmo tempo em que a Lei é normativa - ela é da ordem do imperativo categórico, ou seja, não há como não fazer desse jeito, é um dever, uma obrigação -, a Lei é contingente, no sentido de que é estabelecida e é da ordem do imprevisível. Lacan ainda ressalta que a relação das leis com a transgressão destas na forma do crime, se expressa em todas as sociedades em forma de punições para aqueles que transgridem a lei, ou então, para aqueles que são considerados responsáveis pela conduta criminal que desequilibra o grupo social. O que Lacan ressalta é que a realização destes castigos exige "um assentimento subjetivo", e que este assentimento é "necessário à própria significação da punição" (1998, p.129). Portanto, a significação exige também um assentimento subjetivo a uma lei que vigora. Mas, cabe aqui nos perguntar, que condições são necessárias para que 0 assentimento seja operado.

\section{Método - Estratégias para Produção do conhecimento}

Configura a base deste artigo a pesquisa realizada com adolescentes cumprindo medida socioeducativa em um Cense (Centro de Socioeducação) no Estado do Paraná - Brasil-, na qual foi possível escutar como esses adolescentes significavam suas histórias e seus atos infracionais (Bertol, 2010). A pesquisa em questão foi aprovada pelo Comitê de Etica em Pesquisa com Seres Humanos da UFSC Universidade Federal de Santa Catarina -, bem como, foi elaborado um Termo de Consentimento Livre e Esclarecido (TCLE) assinado pelos entrevistados e por seus representantes legais. No presente artigo analisamos a entrevista realizada com um dos adolescentes participantes dessa pesquisa procurando explicitar como a dinâmica da rede social brasileira culmina muitas vezes na quebra do pacto social e quais os efeitos dessa quebra na constituição subjetiva e na 
vivência das leis. Esclarecemos que o nome do adolescente entrevistado foi alterado. Utilizamos referências psicanalíticas e psicossociais para analisar essa entrevista e entendemos que o fato de transgredir as leis jurídicas não necessariamente explicita uma dificuldade de elaboração da Lei simbólica, descrita como o processo subjetivo responsável por inserir o sujeito na cultura, fazendo-o aceitar as interdições desta.

Carlos é um jovem de 17 anos que foi internado pela segunda vez por assalto a mão armada. Segundo ele estes assaltos tinham como finalidade conseguir dinheiro para usar drogas, sendo que ele achava este caminho mais fácil para conseguir dinheiro do que trabalhar, embora soubesse do perigo que corria. Antes de ser internado ele morava com a mãe e seus irmãos. Eles fugiram do pai porque este era muito violento quando bebia, e inclusive os agredia. Apesar da distância ele ainda busca ter contato com o pai, tem afeto por ele e se preocupa com as condições de sua saúde.

\section{O rompimento do pacto social e seus efeitos no assentimento subjetivo às leis}

Um dos primeiro aspectos que nos chama atenção na entrevista de Carlos é a sua vivência com as leis. Embora ele transgrida as leis jurídicas ele as reconhece como um referencial para suas ações, classificando-as como erradas e principalmente reconhece a importância da existência destas leis. Vejamos alguns trechos de sua entrevista:

Entrevistadora: o que você achou destas punições que você recebeu pelas coisas que você fez? Carlos: ah, eu não achei nada porque eu fiz agora eu tenho que pagar né, to aí um ano e quatro já.

Entrevistadora: mas você acha que deveria ter o castigo? Carlos: ah eu acho que deveria né, porque um monte de gente faz coisa errada né? Entrevistadora: e estas pessoas têm que ser castigadas? Carlos: ah daí da minha parte eu não sei né? Daí vai, ah sei lá, vai da cabeça dos educador empenha os cara. Entrevistadora: uma pessoa que faz algo errado tem que ser castigada? Carlos: igual eu fui? (rindo) Entrevistadora: é. Carlos: ah sei lá né, todo mundo tem que pagar pelo que faz de errado né?

Entrevistadora: o que você acha das leis que existem na sociedade? Carlos: o que eu acho das leis? Eu acho uma grande tiração. Entrevistadora: por quê? Carlos: porque sim. Porque menor não pode trabalhar. Menor não pode trabalhar, então menor pode roubar. Entrevistadora: como assim pode 
roubar? Carlos: não, não pode, mas eles têm, então eles têm que autorizar menor pra roubar. Porque vai ver muitas pessoas que é menor roubam porque precisa. Tem dificuldade, precisa de para sobreviver. Já vi situação assim já.

Entrevistadora: você tem alguma ideia para diminuir o envolvimento de jovens com atos infracionais? Carlos: eles dá serviço pros de menor. Que nem eles queria aprovar, tava aí uma lei, tava pra aprovar uma lei de 16 anos ser de maior já. Eles...e-e-eu acho que eles não aprovaram porque eles viram, eles queriam aprovar pra de menor pagar como maior, só que eles ia...eles tinham que vê que muita coisa ia mudar também. Que nem o menor não pode dirigir que pega multa. Daí de menor com, 16 anos já ia ser maior, daí ia aproveitar e ir pro som, ah sei lá, trabalhar em empresa, ia mudar bastante coisa daí. Só que daí se caísse preso também tava empenhado.

As narrativas do adolescente nos permitem pensar que ele possui um reconhecimento das leis jurídicas, e capacidade de julgar suas ações como certas ou erradas a partir desse código, entendendo inclusive que as punições são um mecanismo necessário para fazer aquele que "faz algo errado, pague" por seus erros. Nesse sentido, os discursos e praticas sociais que entendem que se paga por algo com uma punição atravessam também as narrativas do adolescente e sua subjetividade. As leis, como nos diz Lacan (1998) não apenas são parâmetro de julgamento para aqueles que as transgridem, mas também são basais para organizar as relações e os sentidos das ações daqueles de uma sociedade. Por outro lado, ele percebe que as leis não cumprem a função de assegurar os seus direitos, pelo contrário, não lhe permitem exercê-los, dificultando sua inscrição na rede social pela via do trabalho e a valorização decorrente deste.

Poderíamos pensar que o adolescente reconhece as leis, mas não aceita submeter-se a elas porque isso implicaria em uma restrição das suas satisfações, explicitando uma dificuldade de inscrever a Lei simbólica. Antes dessa conclusão é importante retomarmos as ideias de Pellegrino (1987a) seguindo Freud (1973c; 1973d) que aponta que a obediência às leis envolve não só a inscrição da Lei, mas também o cumprimento do pacto social por parte da sociedade. Esta tem como função proteger o sujeito e oferecer possibilidades de inserção, reconhecimento e satisfação compartilhadas por todos, reconhecendo o sujeito como pertencente a rede social.

Se retomarmos, como exemplo, o Estatuto da Criança e do Adolescente, que dispõe sobre a proteção integral à criança e ao adolescente, encontramos 0 artigo $4^{\circ}$ segundo 0 qual todo adolescente teria direito a segurança, a educação e a profissionalização (BRASIL, 1990). Porém, sabemos que grande parte da população brasileira não tem esses direitos assegurados. As 
narrativas de Carlos a seguir também nos mostram que o acesso a direitos como educação, não são assegurados a todos de forma equivalente.

Entrevistadora: você fazia planos para o seu futuro? Carlos: só ser médico só. Entrevistadora: mas você pensava em como você ia conquistar esse... Carlos: ah sei lá, pra mim era facinho né, daí eu fui crescendo, daí, agora eu vi que não é fácil né. Entrevistadora: e quando você viu que não era fácil, o que você pensou? Carlos: ah eu, agora eu tô começando a estudar mais, e (pausa) prestando atenção na aula.

Analisando as narrativas do adolescente em relação as suas escolhas e possibilidades profissionais, percebemos a lacuna que existe entre seus desejos e suas possibilidades reais marcadas pela dificuldade de oportunidades profissionais. Não obstante a educação e a profissionalização sejam dispositivos exaltados como possibilidades de emancipação e mudança subjetiva e social, eles não são disponibilizados para todos. Grande parte da população é destinada a uma educação de baixa qualidade e aos subempregos, os quais dificultam uma inscrição social adequada, devido a falta de reconhecimento e valorização destas atividades.

Em uma etnografia realizada por Feltran (2011) em uma região periférica da cidade de São Paulo, o autor aponta uma mudança nos modos de vida da geração dos anos 90 nascida nas periferias, pois é uma geração que não crê no projeto de ascensão familiar centrada no trabalho. $O$ autor percebe que o projeto de ascensão pelo trabalho individualizou-se e aparece como menos realizável. O trabalho ainda é um valor central para os jovens dessa geração, mas os significados atribuídos a ele já não são os mesmos, ele é uma fonte para o consumo de objetos e os ideais profissionais para a ascensão pendem para o futebol, a música ou a carreira artística. Para aqueles que não têm possibilidade de trabalhar e não alcançam o mundo da fama, há a possibilidade de obter renda em atividades criminais, mas não somente renda é obtida. O mundo do crime possibilitaria obter o que o trabalho traria: renda, consumo e o aumento do status individual no grupo.

As falas de Carlos possibilitam pensar que embora o trabalho seja uma via que viabiliza obter reconhecimento e inserção social os subempregos destinados aos adolescentes de periferia não operam da mesma forma, pois devido a sua precariedade e baixa valorização impossibilitam a construção de objetos e lugares valorizados no campo social. Essas análises reforçam as análises de Pellegrino (1987a) de que o que se passa no pacto social produz efeitos no pacto edípico. 
No caso de Carlos percebemos como ele sustenta a busca por uma profissão valorizada socialmente. Porém, suas condições econômicas e sociais dificultam seu acesso a uma faculdade de medicina, o que obviamente não impede que algumas pessoas consigam superar suas dificuldades na busca por seus objetivos. O que nos chama atenção aqui são os efeitos no adolescente dos princípios liberais na relação com o campo social. Sua narrativa expressa o engodo de que as oportunidades de realização profissional são dadas a todos igualmente, tanto é que atribui a dificuldade de alcançar a profissão de médico ao fato de não estudar, tomando somente para si a responsabilidade por não realizar seu objetivo. Esse discurso vela o fato de que não são todos que apresentam as mesmas condições sociais e nem terão as mesmas oportunidades. Por outro lado, Carlos percebe que as oportunidades de subemprego que são destinadas aos jovens de periferia como ele não são valorizadas, nem por ele e nem pelos outros, e não the permitirão uma ascensão social.

Retomando os estudos de Souza (1999) sobre as experiências com a lei no Brasil a autora resgata a incorporação do projeto moderno liberal pela sociedade brasileira, apontando como este projeto sofreu modificações principalmente no que se refere ao princípio de igualdade, com vistas a manter o poder entre a elite dominante. Isso porque sua implantação implicava na reorganização social objetivando preservar os indivíduos das desigualdades geradas por fatores hereditários e familiares que colocava parte da população em desamparo. A autora nos mostra que foram feitas adaptações buscando adequar esse projeto a realidade escravocrata e oligárquica nacional da época. Assim, embasada em teorias raciais importadas da Europa, a elite dirigente do Brasil fundamentava as diferenças sociais em diferenças biológicas e com isso estabelecia critérios diferenciados para a cidadania e para os direitos.

A busca por efetivar a igualdade como princípio organizador do campo social ressurgiu após a ditadura brasileira enquanto projeto político (Feltran, 2011), porém, um olhar sobre a população que ocupa de forma massificada as prisões nacionais, e as condições de vida precárias as quais são submetidas grande parte da população demonstram que a igualdade ainda é algo a ser alcançado. Assim, como nos diz Carlos, a educação ainda é privilégio daqueles que detém uma boa condição econômica, principalmente no ensino superior. Embora existam políticas afirmativas buscando superar as desigualdades que existem no país, ainda vemos que a vivência da cidadania por todos não é uma realidade. Dessa forma, temos uma legislação formal que se constitui embasada pelos princípios de liberdade e igualdade, mas que na prática se exerce de forma desigual. Essa desigualdade tem como efeito a quebra do pacto social, o qual se funda na lei da cidadania, da igualdade e justiça para todos. 
O rompimento do pacto social, pelo desrespeito aos direitos de grande parte da população, rompe também com o movimento de troca necessário ao assentimento subjetivo ao mesmo o que pode fazer com que ocorra a não legitimação das leis jurídicas com conseqüente produção em parte dessa população de novas práticas e regras sociais que passam a funcionar como leis para regular suas relações sociais. É o que nos mostram o trabalho de Souza (1999) sobre a experiência com a lei e a etnografia realizada por Feltran (2011), na qual o autor aponta como o crime é uma organização que faz parte das periferias e é a quem muitas vezes a população pode recorrer para ter seus direitos assegurados. Além disso, o crime também traz respeito, não só àqueles que participam ativamente, mas também para aqueles que transitam entre as fronteiras do "mundo certo" e o "mundo errado".

O crime ocupa espaços que o estado não ocupa, ou ocupa de forma violenta, o que leva a descrença da população nesta instância como protetora de seus direitos. Produzem-se então subjetividades que articulam a vivência da lei de forma distinta daquelas produzidas nas sociedades modernas. Essas pessoas associam suas vivências a outras representações e outros modelos identificatórios constituídos a partir de sua realidade social (Pellegrino, 1987b; Souza, 1999). Em outras palavras, a descrença nos poderes legislativo, executivo e judiciário leva a descrença na lei, pois estes poderes falham em reger as relações sociais entre os sujeitos. A descrença no poder público, as promessas e expectativas embasadas nos princípios de liberdade e igualdade que são frustradas quando se inscrevem na realidade social, acabam criando um vazio institucional que é ocupado muitas vezes por organizações vinculadas a um mundo ilegal.

Estas leituras nos possibilitam questionar se aqueles que transgridem as leis o fazem por uma dificuldade em aceitar as perdas oriundas das interdições que se produzem com a inscrição da Lei, ou se o que ocorre é que embora a inscrição subjetiva da Lei opere, as vivências com as leis jurídicas e com as demandas postas pelos ideais capitalistas dificultam que essa inscrição seja sustentada. Nas narrativas descritas, Carlos nos mostra que embora não cumpra algumas das prescrições formais jurídicas, ele se referencia e assente a outro código normativo, o do mundo do crime, o qual passa a ser respeitado, temido e valorizado.

Entrevistadora: como você se sentia quando você respeitava as regras do grupo que você convivia na rua? Carlos: eu sentia normal, porque eu sempre respeitava, eu nunca fiz nada de...que, desacatasse as regras dos ladrão. Entrevistadora: e o que você acha das pessoas que desacatam essas regras? Carlos: tem que morrer né. Entrevistadora: o que você acha delas? Carlos: ah eu acho que elas não serve pro, pro mundo 
do crime. Tem que virar um crente, sei lá, tem que parar de roubar.

Entrevistadora: e além da proibição de caguetar tem mais alguma? Carlos: ah, estuprar também é embaçado né. Entrevistadora: qual a diferença entre roubar alguém, matar alguém e estuprar alguém? Carlos: ah ixi, é, ixi, é sei lá, eu não sei explica, mas é, pra mim é muito embaçado. Pense um cara de 50, 40 anos indo estuprar uma criança de...recém nascido. Entrevistadora: e alguém matar um recém nascido? Carlos: ixi, é foda, é embaçado mesmo. Entrevistadora: têm pessoas que podem ser mortas e pessoas que não? Carlos: ah matar alguns é certo né? Estuprador, cagueta, quem mata criança, quem mata mulher, tudo pode morrer.

Inicialmente, podemos inferir que a obediência de Carlos ao código de "regras do ladrão" pode ocorrer devido ao temor pelas severas punições que sofrem aqueles que não cumprem estas regras. Porém, a sua obediência parece ir além do medo, pois ele demonstra reconhecer-se nestas leis, concordar com elas e valorizar a necessidade de sua existência para regular as ações entre os sujeitos. Ele demonstra que sua conduta é regida por uma ética que embora se construa com base no código do crime ainda sim serve como referência para suas ações, e quebrar este código seria algo desonroso. Apesar de severo, este código de leis regula as relações do sujeito com o outro e com a rede social, e percebemos que apesar de que alguns aspectos difiram das leis jurídicas e sociais, as regras do mundo do crime também se encontram e compartilham de muitas regras jurídicas e sociais.

O respeito e o prestigio obtidos a partir do comprometimento com "as regras do ladrão" produzem efeitos subjetivos importantes nos adolescentes. Isso porque tal como os pais fazem um investimento no sujeito, construindo um lugar no seu desejo e permitindo que este se constitua, o campo social também investe o lugar que o sujeito deve ocupar, ou seja, o grupo transmite normas, lugares ideais, modelos referentes a organização social e aponta quem pode ou não ocupá-los e desfrutar dos mesmos. O que está em jogo novamente é o desejo do Outro e o lugar que se pode ocupar neste, o assujeitamento a este desejo como forma de existir enquanto sujeito, pois é vital o reconhecimento para que essa existência se dê (Rosa, 2002).

Assim, embora seus atos sejam criminosos do ponto de vista das leis jurídicas, isso não significa que a subjetividade de jovens como Carlos seja caracterizada por uma falta de inscrição da Lei, ou então por um uso particular desta Lei. Pelo contrário, no caso de Carlos, o código de leis "do ladrão" serve como referência mesmo quando envolve sua relação com seu objeto eleito de satisfação: a droga. Carlos 
reconhece os efeitos da droga sobre ele e procura fazer tudo "certinho", mesmo que isso implique na falta do seu objeto de satisfação. Em uma conversa com Carlos, ele nos conta que nunca ficou devendo para o tráfico, pois entendia que isso era uma vergonha. Quando queria usar drogas, ele roubava para ter dinheiro, e se não conseguisse não usava, mas nunca pensava em descumprir as leis do crime para obter drogas.

Por outro lado, é relevante apontar, ainda, que a inscrição subjetiva da Lei é explicitada em outras situações que não somente a obediência a um código de leis, mas também na inscrição do outro em sua subjetividade. A seguir apresentamos alguns trechos que tratam de como a questão da alteridade se inscreve em Carlos.

Entrevistadora: e o que é a curtição? Carlos: ah, ir pras balada, ficar com a mulherada. Entrevistadora: é o que você quer pra sua vida? Carlos: ah, eu não quero pra minha vida. Eu quero terminar meus estudos, fazer vestibular pra medicina. É um sonho que eu tenho desde pequenininho já. Entrevistadora: de onde esse sonho de ser médico? Carlos: ah (pausa) por ajudar as pessoas, sei lá. Eu acho bom assim salvar as pessoa.

Entrevistadora: que tipo de ajuda? Carlos: ah tipo assim, que nem ch...tipo assim, um cara, sempre tinha um véio bêbado assim que passava lá em casa. Ele vivia passando pedindo comida na casa dos outro. Ele passava lá em casa e pedia e eu sempre arrumava um negócio pra ele. Daí ele passava direto lá e eu sempre dava comida pra ele assim. Uma vez ele tava doentão assim lá na rua assim, deitado assim, eu peguei e levei ele lá no médico. Aí as mulher queriam me dar até um dinheiro, aí eu falei: 'ah eu não quero dinheiro'. Entrevistadora: você não aceitou? Carlos: não. Entrevistadora: por que? Carlos: ah porque não né, queria me dar dinheiro.... dinheiro eu tenho. Entrevistadora: mas você não roubava pra ter dinheiro...? Carlos: não, mas não é, eu-eu-eu fiz aquilo lá não é pra ganhar dinheiro, pra mim ajudar ele! Então se tiver uma, mes...mesma coisa assim, uma pessoa que não anda assim, numa cadeira de rodas assim pedir uma ajuda, e eu fala bem assim, quanto você vai cobrar pra me ajudar a atravessar a rua ali? Você vai cobrar da pessoa? É a mesma coisa.

Por suas narrativas percebemos como a presença do outro é fundamental na sua subjetividade, proporcionando-Ihe tanto experiências insatisfatórias como satisfatórias. Ao mesmo tempo em que percebemos um movimento em busca de autonomia, percebemos que o outro atua efetivamente em sua subjetividade, seja Ihe apontando a distância entre suas realizações e um ideal, seja 
proporcionando-Ihe experiências de satisfação por meio de vivências afetivas e reconhecimento em sua rede social. Ele inclusive demonstra pautar suas ações por aquilo que 0 faz obter reconhecimento das pessoas que compartilham de sua rede social. Demonstra também uma preocupação com o outro no sentido de mostrar-se disposto a ajudar aqueles com os quais se identifica e produz empatia.

Perguntamos então o que leva Carlos a cometer seus atos infracionais uma vez que possui uma inscrição simbólica da Lei, e mostra-se capaz de assentir subjetivamente a um código de leis. Algumas falas do adolescente nos indicam outros sentidos para seus atos infracionais.

Carlos: ah eu tava armado, daí os cara vinham, vinham me tirar, sempre achavam que porque eu era pequenininho achavam: 'ah um piazinho de bosta, ah não guenta nada'. Eu com uma arma na mão era só eu puxar e dar um tiro na cara do cara. Entrevistadora: e o que você fazia? Carlos: ah eu ficava na minha. Entrevistadora: você aguentava a tiração? Carlos: guentava, ficava de boa...não não é que eu aguentava a tiração, eu ficava na minha, se o cara eu...tipo assim, o cara só falava, eu falava pro o cara, falava: 'ò cara (pausa) não fale mais que quem fala demais amanhece com a boca cheia de formiga'. Daí o cara ficava quieto, não ficava me tirando, porque o cara sabia que eu tava armado.

O discurso de Carlos nos permite pensar que por um lado ocorre a ruptura do pacto social, devido às desigualdades sociais e a exclusão social, dificultando a sua inserção na rede social a partir de um lugar valorizado. Por outro lado, a sua inserção no mundo do crime e o compartilhamento de suas práticas Ihe possibilitam uma valorização dentro desse grupo, bem como, oferecem modelos identificatórios. Referimo-nos as possibilidades de identificação com uma figura masculina, que são encontradas por Carlos na rede social e no mundo do crime. Pesquisadoras como Cecchetto (2004) e Machado (2004) apontam que apesar dos inúmeros estudos sobre gênero demonstrarem que as representações sobre masculinidade e feminilidade são produzidas e associadas ao sexo biológico a partir do contexto sócio-histórico, ainda permanece a concepção que entende a agressividade como um atributo natural e essencial do homem. A autora demonstra como existem relações de poder não somente intergênero, mas também intragênero, constituindo uma hierarquia simbólica na qual as diferentes figuras masculinas se posicionam de acordo com os valores e significados que são compartilhados pela rede social. 
A representação valorizada tanto pela rede social em geral, quanto pelo mundo do crime, associa o masculino ao domínio, entendendo-o como aquele que impõe sua vontade ao outro ao invés de subordinarse a ele. A inserção de Carlos no mundo do crime, concomitante ao porte de armas, possibilitam a sua identificação com uma representação masculina agressiva e potente, e sem a qual se sente desamparado, ameaçado pelo outro. Zaluar (1999) demonstra como o porte de armas possibilita um fortalecimento da representação identitária masculina, pois, o próprio ato violento encontra-se ligado à representação de masculinidade. $O$ masculino é aquele que defende seu espaço por meio da violência ou da ameaça, o que faz com que o sujeito se sinta mais viril e masculino. Sem a arma, Carlos volta a se sentir vulnerável e ameaçado perante o outro, o que faz com que perceba a ilusão envolvida no sentimento de potência e força que surgem a partir da posse de arma, não tendo o poder de realmente transformá-lo ou torná-lo mais forte. Mas, por outro lado, a arma possibilita um sentimento real de segurança diante do outro, constituído por suas experiências nas quais não mais é violentado, mas pelo contrário, passa a ser respeitado e temido.

Portanto, se por um lado, o assentimento ao pacto social oportuniza a Carlos uma inserção social desvalorizada, que se opera por meio de subempregos, os quais dificultam a obtenção de um reconhecimento e uma valorização dentro da rede social, bem como, podem levá-lo a identificar-se com uma representação identitária masculina desvalorizada. Por outro lado, a sua inserção no mundo do crime e o assentimento ao seu código de leis parece possibilitar um reconhecimento social e a identificação com uma representação identitária masculina valorizada.

\section{Considerações finais}

As experiências singulares e coletivas parecem ter permitido a Carlos uma inscrição da Lei simbólica e uma aceitação da interdição, porém a desobediência às leis jurídicas parece ocorrer devido a não legitimação do pacto social, a qual ocorre pela própria dinâmica social, que exclui parte da população e não cumpre sua parte contratual. Embora em um primeiro momento possa parecer que aquele que comete atos infracionais e descumpre as leis jurídicas também recusa a inscrição da Lei, as narrativas de Carlos nos apontam o fato de que tanto a inscrição da Lei como os atos infracionais envolvem outros processos psíquicos e sociais e, portanto, não podem ser reduzidos ao cumprimento das leis jurídicas. A operação de inscrição da Lei envolve a inscrição de uma alteridade, a possibilidade de orientar o desejo e constituir uma representação identitária sexual, bem como orientar a escolha de objeto sexual, a 
partir da formação de ideais, os quais são constituídos no entrecruzamento das identificações com as instâncias parentais e dos valores sociais. Entretanto, a operação de troca, necessária para que o sujeito se submeta à Lei e à lei (Pellegrino, 1987a), nem sempre ocorre, conforme foi possível apontar neste trabalho.

Salienta-se que a extrema desigualdade social e a relação de força presentes na rede social capitalista produzem leis formais distantes da realidade da maioria das pessoas, e que em muitos casos torna-se opressora e violenta, o que as leva a não se reconhecerem no aparato jurídico. Assim, temos que grande parte da população não acredita na lei formal, e a prática transgressiva pode assumir outros sentidos para aqueles que cometem atos infracionais. Carlos vivencia a falta de reconhecimento dentro da rede social, já que nas suas relações com as leis manifesta-se uma condição de desamparo, traduzida na falta de direitos e na falta de oportunidades de assumir e realizar os ideais e os valores sociais impostos. Assim, pudemos analisar que a troca necessária para a subordinação às leis nem sempre ocorre. Entretanto, o jovem demonstra a legitimação de um código de leis presente no mundo do crime e que o cumprimento deste possibilita a obtenção do reconhecimento do grupo pela assunção da figura do "delinquente".

O que procuramos problematizar com este trabalho é que embora alguns adolescentes não cumpram as leis jurídicas e não se adequem a modelos sociais moralmente aceitos, isso não implica a priori uma recusa da Lei e uma constituição subjetiva anômala. O que pode ocorrer é um processo de desvalorização das próprias leis jurídicas pela desigualdade em sua aplicação por parte do Estado e de suas instituições; associada à dissociação das leis formais com a realidade experimentada pela maioria dos legislados; juntamente com a valorização da figura masculina agressiva realizada por meio das práticas do crime. Importante salientar aqui que a identificação com uma figura masculina correlata dos atributos de domínio e agressividade é alcançada de diferentes formas, e que se encontra presente em diversas práticas sociais que não somente os atos infracionais. Os atos infracionais são uma forma de identificar-se com esta representação, devido às possibilidades sociais e econômicas que oferecem. No caso de adolescentes em conflito com a lei, a produção de valores que idealizam a masculinidade fálica e a posse de objetos (mercadorias e domínio do outro) ao lado do contexto socioeconômico deste jovem possibilita que eles busquem realizar esses ideais a partir da transgressão de algumas leis. Podemos entender, então, que não necessariamente esta transgressão representa uma recusa da Lei, pelo contrário, é por terem inscrito a Lei e partilharem dos valores da rede simbólica e social na qual esta operação os inscreve que eles procuram envolver-se com atos infracionais. Assim, entendemos que o fato de o sujeito desrespeitar 
as leis não significa necessariamente uma falta de inscrição da Lei, sendo que o contrário também se sustenta, pois não podemos afirmar a priori que aquele que cumpre as leis tenha uma inscrição simbólica da Lei.

\section{Referências}

Bertol, C. E. (2010). Inscrição da Lei, constituição subjetiva e masculinidades: cenas de adolescentes cumprindo medida socioeducativa. Dissertação de Mestrado, Curso de Pós Graduação em Psicologia, Universidade Federal de Santa Catarina, Florianópolis, SC.

Bobbio, N. (1997). Dicionário de Política. 9. ed. Brasília: Editora Universidade de Brasília.

Brasil. (1990). Estatuto da Criança e do Adolescente. Lei Federal $n^{\circ}$ 8069 de 13 de julho de 1990, Brasília, DF.

Cecchetto, F. R. (2004). Violência e estilos de masculinidade. Rio de Janeiro: Editora FGV.

Feltran, G. (2011). Fronteiras de tensão. Política e violência nas periferias de São Paulo. São Paulo: UNESP.

Freire Costa, J. (2003). Violência e psicanálise. Rio de Janeiro: Graal.

Freud, S. (1973a). Psicologia de las masas y analisis del "yo". In: Freud, S. Obras Completas. (v. III, pp. 2563-2610). Madrid: Editorial Biblioteca Nueva. (Trabalho original publicado em 1921).

Freud, S. (1973b). El yo y el ello. In: Freud, S. Obras Completas, v. III (pp. 2701-2728). Madrid: Editorial Biblioteca Nueva. (Trabalho original publicado em 1923).

Freud, S. (1973c). El malestar en la cultura. In: Freud, S. Obras Completas, v. III (pp. 3017-3067.) Madrid: Editorial Biblioteca Nueva. (Trabalho original publicado em 1930).

Freud, S. (1973d). El porque de la guerra. In: Freud, S. Obras Completas, v. III (pp. 3207-3215). Madrid: Editorial Biblioteca Nueva. (Trabalho original publicado em 1932).

Freud, S. (2012). A responsabilidade moral pelo conteúdo dos sonhos. In: Obras Completas, v. 16 (pp. 324-328).

São Paulo: Companhia das Letras. (Trabalho original publicado em 1925).

Lacan, J. (1998). Introdução teórica às funções da psicanálise em criminologia. In: Escritos. (pp. 127-151). Rio de Janeiro: Jorge Zahar. (Trabalho original publicado em 1950).

Lacan, Jacques. (1999). O seminário, livro 5: As formações do inconsciente. Rio de Janeiro: Jorge Zahar. (Seminário ministrado em 1957-1958). 
Machado, L. Z. (2004) Masculinidades e violências: gênero e malestar na sociedade contemporânea. In: Schpun, M. R. (Org). Masculinidades. (pp. 35-78). São Paulo: Boitempo Editorial.

Paraná. (2006). Instituto de Ação Social do Paraná. Cadernos do Iasp: Compreendendo o adolescente. Paraná: Imprensa oficial do Paraná.

Pellegrino, H. (1987a). Pacto edípico e pacto social. In: Py, L. A. (Org.) Grupo sobre grupo. (pp. 195-205). Rio de Janeiro: Rocco.

Pellegrino, H. (1987b). Édipo e a paixão. In: Novaes, A. (Org.) Os sentidos da paixão (pp. 307-328). São Paulo: Companhia das Letras.

Rosa, M. D. (2002). Adolescência: da Cena Familiar à Cena Social. Psicologia USP, 13, 2, 227-241. Disponível em: <http://www.scielo.br/scielo.php?script=sci_arttext\&pid=S010 3-65642002000200013\&lng=pt\&nrm =iso >.

Souza, M. (1999). A experiência da lei e a lei da experiência: ensaios sobre práticas sociais e subjetividades no Brasil. Rio de Janeiro, São Paulo: Revan, FAPESP.

Zaluar, A. (2004). Violência, cultura e poder. In: Cecchetto, F. R. Violência e estilos de masculinidade. (Prefácio, pp. 7-34). Rio de Janeiro: Editora FGV.

Waiselfisz, J. J. (2014). Mapa da violência: Os jovens do Brasil. Brasília: Secretaria Nacional da Juventude.

\section{Endereço para correspondência \\ Carolina Esmanhoto Bertol}

Pontifícia Universidade Católica de São Paulo - PUCSP

Rua Ministro Godoy, 969, 40 andar, Perdizes, CEP 05015-901, São Paulo - SP, Brasil

Endereço eletrônico: carolbertol@hotmail.com

\section{Mériti de Souza}

Universidade Federal de Santa Catarina - UFSC

Departamento de Psicologia - Centro de Filosofia e Ciências Humanas

Campus Universitário, Trindade, CEP 88040-500, Florianópolis - SC, Brasil

Endereço eletrônico: meritisouza@yahoo.com.br

Recebido em: 30/06/2015

Reformulado em: 31/05/2017

Aceito em: 04/06/2017

\section{Notas}

* Psicóloga. Psicanalista. Mestre em Psicologia pelo Programa de Pós-Graduação em Psicologia da UFSC - Universidade Federal de Santa Catarina - Brasil.

** Professora no Programa de Pós Graduação em Psicologia na UFSC Universidade Federal de Santa Catarina - Brasil. Psicóloga. Doutora em Psicologia Clínica pela PUCSP - Pontifícia Universidade Católica de São Paulo. Pós-Doutorado no CES - Centro de Estudos Sociais - da Universidade de Coimbra. Endereço para 
correspondência: Departamento de Psicologia - CFH - UFSC - Campus Trindade 88040910 - Florianópolis - Brasil. 